Pesq. Vet. Bras. 28(9):393-398, setembro 2008

\title{
Avaliações radiográfica e ultra-sonográfica do joelho de ovinos $^{1}$
}

\author{
Khadije Hette ${ }^{2 \star}$, Sheila Canevese Rahal ${ }^{3}$, Maria Jaqueline Mamprim ${ }^{4}$, \\ Reinaldo dos Santos Volpi ${ }^{5}$, Vicente Colombi da Silva ${ }^{6}$ e Danilo Otávio \\ Laurenti Ferreira ${ }^{7}$
}

\begin{abstract}
Hette K., Rahal S.C., Mamprim J.M., Volpi R.S., Silva V.C. \& Ferreira D.O.L. 2008. [Radiographic and ultrasonographic evaluations of the ovine stifle joint.] Avaliações radiográfica e ultra-sonográfica do joelho de ovinos. Pesquisa Veterinária Brasileira 28(9):393-398. Departamento de Cirurgia e Anestesiologia Veterinária, Faculdade de Medicina Veterinária e Zootecnia, Universidade Estadual Paulista, Distrito de Rubião Junior s/n, Botucatu, SP 18650-000, Brazil. E-mail: khadijehette@yahoo.com.br

The aim of this study was to evaluate the stifle joint of 18 healthy Santa Ines sheep in different age groups, utilizing both radiographic and ultrasonographic exams. The animals were divided into 3 equal groups: Group I, 6-8 months old (mean weight of 25 $\mathrm{kg}$ ); Group II, 2 years old (mean weight of $50 \mathrm{~kg}$ ); Group III, 3-5 years old (mean weight of $55 \mathrm{~kg}$ ). Radiographically the lateral femoral condyle was larger than medial femoral condyle, and the lateral tibial condyle was larger than the medial tibial condyle in the craniocaudal view. The patella showed a pyramidal base and a pointed apex in mediolateral view. The medial sesamoid bone of the gastrocnemius muscle was observed in one, and the lateral sesamoid bone was observed in four of 36 hindlimbs evaluated. Out of all the radiographs, the fibula was identified in only one animal - a Group III sheep. The distal femoral, proximal tibial and tibial tuberosity physes could be evaluated in all radiographs. These physes were closed or semiclosed in all animals of Group III. According to ultrasonographic examination, the convex surface of the patella was observed as a hyperechogenic line with an acoustic shadow and the articular cartilage of the femoral condyles was observed as a hypoechogenic line outlining the bone surface. The intermediate patellar ligament presented as a fibrilar hyperechogenic structure measuring 1.2-3.2 $\mathrm{mm}$ in thickness. The lateral and medial menisci appeared triangular in shape, slightly heterogeneous, and moderately echogenic. In conclusion, the radiographic images were useful to evaluate the bone structures of the stifle, and physis closure and the ultrasonographic images allowed to identify soft tissue structures, such as menisci and patellar ligament.
\end{abstract}

INDEX TERMS: Joint, stifle, imaging methods, sheep.

\footnotetext{
${ }^{1}$ Recebido em 8 de janeiro de 2008.

Aceito para publicação em 22 de agosto de 2008.

2 Programa de Pós-Graduação em Medicina Veterinária, área de Cirurgia, Veterinária, Faculdade de Medicina Veterinária e Zootecnia (FMVZ), Universidade Estadual Paulista (Unesp), Cx. Postal 560, Distrito de Rubião Junior s/n, Botucatu, SP 18650-000, Brasil. *Autor para correspondência: khadijehette@yahoo.com.br

${ }^{3}$ Departamento de Cirurgia e Anestesiologia Veterinária, FMVZ, Unesp-Botucatu.
}

\footnotetext{
${ }^{4}$ Departamento de Reprodução Animal e Radiologia Veterinária, FMVZ, Unesp-Botucatu.

${ }^{5}$ Departamento de Cirurgia e Ortopedia, Faculdade de Medicina, Unesp-Botucatu, Cx. Postal 539, Distrito de Rubião Junior s/n, Botucatu, SP 18650-000.

${ }^{6}$ Programa de Residência (R2) em Medicina Veterinária, FMVZ, Unesp-Botucatu.

7 Programa de Pós-Graduação em Medicina Veterinária, FMVZ, Unesp-Botucatu.
} 
RESUMO.- Com o presente trabalho visou-se estudar as características osteo-articulares do joelho de ovinos hígidos em diferentes idades, considerando duas possibilidades de exames: radiográfico e ultra-sonográfico. Foram utilizados 18 ovinos da raça Santa Inês, divididos em três grupos experimentais eqüitativos: Grupo I, idade de 6-8 meses (peso médio de $25 \mathrm{~kg}$ ); Grupo II, idade de 2 anos (peso médio de $50 \mathrm{~kg}$ ); Grupo III, idade de 3-5 anos (peso médio de $55 \mathrm{~kg}$ ). Radiograficamente, na incidência craniocaudal, o côndilo femoral lateral apresentou-se mais amplo que o côndilo medial, assim como o côndilo tibial lateral foi maior em relação ao medial. A patela apresentava base em formato piramidal e ápice afilado na incidência mediolateral. Dos 36 membros avaliados, o osso sesamóide medial do músculo gastrocnêmio foi visibilizado em apenas um membro e o osso sesamóide lateral em quatro. A fíbula foi identificada somente em um animal do Grupo III. As linhas fisárias femoral distal, tibial proximal e da tuberosidade da tíbia puderam ser avaliadas em todas as radiografias, estando fechadas ou semifechadas especialmente nos ovinos do Grupo III. Ao exame ultrasonográfico, a superfície convexa da patela foi visibilizada como uma linha hiperecogênica com sombra acústica e a cartilagem articular dos côndilos femorais como uma linha hipoecogênica contornando a superfície óssea. O ligamento patelar intermédio mostrou-se como uma estrutura fibrilar hiperecogênica homogênea com espessura de 1,2 a 3,2mm. Os meniscos lateral e medial apresentaram formato triangular, aspecto discretamente heterogêneo e ecogenicidade moderada. Sendo assim, o exame radiográfico foi útil para avaliar especialmente as estruturas ósseas do joelho e o fechamento da placa fisária, e a ultra-sonografia permitiu identificar algumas das estruturas teciduais moles, como os meniscos e o ligamento patelar.

TERMOS DE INDEXAÇÃO: Articulação, joelho, métodos de imagem, ovino.

\section{INTRODUÇÃO}

A anatomia do joelho envolve a porção óssea (fêmur distal, tíbia proximal e patela), os ligamentos cruzados (cranial e caudal), os meniscos, os estabilizadores mediais e laterais, e a musculatura do quadríceps (Sisson 1986a, Allen et al. 1998). A articulação do joelho em ovinos é diartrodial e bastante similar a dos seres humanos, porém com variações tais como a presença do tendão do músculo extensor longo dos dedos no aspecto craniolateral da articulação, a ausência do ligamento menisco-femoral cranial no espaço articular caudal, e a origem difusa do ligamento patelar nos dois terços proximais do aspecto dorsal da patela (Allen et al. 1998). Desta forma, esta pode ser considerada um bom modelo para estudos relacionados ao transplante de menisco, ruptura de ligamento cruzado, transplante de cartilagem e transplante articular, entre outros (Jackson et al. 1992, Dürselen et al. 1996, Szomor et al. 2000, Kelly et al. 2006).
Dentre os exames auxiliares atualmente utilizados para avaliar o joelho estão os não invasivos, tais como radiografia, ultra-sonografia, ressonância magnética e tomografia computadorizada, e os invasivos como a artroscopia, cada um com suas vantagens e desvantagens (Carrig 1997). As radiografias de alta qualidade são precisas em identificar mudanças estruturais resultantes de doença articular degenerativa, porém o diagnóstico pode ser desafiador nos estágios iniciais da doença (Widmer \& Blevins 1994, Carrig 1997, Mahaffey 1998), além da exposição à radiação ionizante (Carrig 1997, Freeman \& Pinskerova 2003). Por sua vez, o exame ultra-sonográfico apresenta vantagens como não usar a radiação ionizante e permitir a avaliação direta da cartilagem articular e da membrana sinovial, e como principal desvantagem a impermeabilidade do osso às ondas sonoras, que limita o acesso a determinadas regiões das articulações (Reed et al. 1995, Carrig 1997).

Visto que em muitas situações, mais que uma modalidade de avaliação é necessária para determinar a presença e a extensão da doença (Stickle \& Hathcock 1993, Widmer et al. 1994, Torelli et al. 2004), o presente trabalho visou estudar as características radiográficas e ultra-sonográficas do joelho de ovinos hígidos em diferentes idades.

\section{MATERIAL E MÉTODOS}

A metodologia adotada durante o desenvolvimento do presente trabalho foi aprovada pela Câmara de Ética em Experimentação Animal da Faculdade de Medicina Veterinária e Zootecnia da Universidade Estadual Paulista (Unesp), Botucatu (Protocolo $\left.n^{\circ} 25 / 2006\right)$.

Foram utilizados 18 ovinos hígidos da raça Santa Inês, 12 machos e 6 fêmeas, divididos em três grupos experimentais eqüitativos: Grupo I, idade de 6-8 meses (peso médio de 25 $\mathrm{kg}$ ); Grupo II, idade de 2 anos (peso médio de $50 \mathrm{~kg}$ ); Grupo III, idade de 3-5 anos (peso médio de $55 \mathrm{~kg}$ ). Os animais foram vermifugados $^{8}$, numerados de 1 a 18 e alocados em baias de $2,5 \times 2,5 \mathrm{~m}$ (três indivíduos por baia), onde receberam água e feno ad libitum, além do fornecimento diário de ração de manutenção processada com $16 \%$ de proteína.

Para realização dos exames radiográficos os animais, em jejum prévio de 24 horas, foram inicialmente tranqüilizados com acepromazina $^{9}$, na dose de $0,03 \mathrm{mg} / \mathrm{kg}$ pela via intravenosa. Decorridos 10 minutos, a anestesia dissociativa foi induzida e mantida com combinação de cetamina ${ }^{10}(3 \mathrm{mg} / \mathrm{kg})$ e diazepam ${ }^{11}$ $(0,5 \mathrm{mg} / \mathrm{kg})$, administrada por via intravenosa. As radiografias foram efetuadas nas projeções mediolateral e craniocaudal, incluindo as articulações femorotibiopatelar e tibiotársica. Para a projeção mediolateral, os animais foram posicionados em decúbito lateral direito e esquerdo, com o membro pélvico mantido em posição anatômica de estação. A articulação do joelho foi mantida em torno de $140^{\circ}$ e a tibiotársica em torno $150^{\circ}$, estando os côndilos femorais sobrepostos. Para obter um ali-

\footnotetext{
${ }^{8}$ CYDECTIN NF, Fort Dodge, Rua Luiz Fernando Rodrigues 1701, Campinas, SP.

${ }^{9}$ ACEPRAN, Univet, Rua Clímaco Barbosa 700, São Paulo, SP.

${ }^{10}$ VETASET, Fort Dodge, Rua Luiz Fernando Rodrigues 1701, Campinas, SP.

${ }^{11}$ COMPAZ, Cristália, Rodov. Itapira-Lindóia, Km 14, Itapira, SP.
} 
nhamento correto na projeção craniocaudal, os ovinos foram posicionados em decúbito dorsal com os membros pélvicos tracionados caudalmente, paralelos entre si e a mesa de exame, o que manteve as articulações do quadril e do joelho em máxima extensão. Os joelhos foram estendidos e rotacionados medialmente, e a patela foi centralizada sobre o sulco troclear.

Utilizou-se aparelho de raios- $x^{12}$ com capacidade para $125 \mathrm{kVp} / 500 \mathrm{~mA}$, equipado com grade antidifusora de PotterBucky. O filme foi da marca Kodak ${ }^{13}$, base verde, com tamanhos variados de acordo com o porte do animal. As películas foram contidas em chassi metálico com écrans reforçadores ${ }^{14}$, sendo a distância foco-filme de $90 \mathrm{~cm}$. A exposição foi de $45 \mathrm{kV}$ e 3,2mA para a projeção mediolateral e $50 \mathrm{kV}$ e 3,2mA para a projeção craniocaudal. Após exposição radiográfica, as películas foram identificadas por impressão luminosa e processadas em reveladora para filmes de raios- $x$ automática ${ }^{15}$.

Foram avaliados os aspectos da anatomia radiográfica do joelho, com especial atenção a patela, tróclea, côndilos do fêmur e da tíbia, platô tibial, protuberâncias das inserções dos ligamentos, espaço articular e coxim gorduroso, presença e localização (medial ou lateral) de osso sesamóide do músculo gastrocnêmio, aspecto da fíbula vestigial, presença (aberta ou semifechada) ou ausência da linha radiolucente das placas fisárias do fêmur distal, tíbia proximal e tuberosidade da tíbia. A superfície do osso subcondral dos côndilos femorais - medial e lateral - foi classificada como lisa ou irregular (Grau 1, discreto; Grau 2, moderado; Grau 3, severo).

Os exames ultra-sonográficos foram efetuados com os ovinos imobilizados por contenção física em decúbito lateral sobre mesa própria, posicionados do lado direito do examinador, com a região cefálica paralela ao aparelho e a pélvica ao lado do examinador. O aparelho de ultra-som utilizado foi o LOGIQ 3 da marca $\mathrm{GE}^{16}$, com transdutor linear multifrequencial de 7,5$10 \mathrm{MHz}$, empregando-se a maior freqüência.

A tricotomia compreendeu o terço distal do fêmur até a região distal da tuberosidade tibial. Após aplicação de gel acústico, o joelho foi submetido à varredura eletrônica nos eixos longitudinal e transversal, com o transdutor posicionado de maneira que a visão longitudinal do aspecto proximal da articulação femorotibiopatelar ficasse à esquerda do monitor e o aspecto distal à direita. No plano transversal, o aspecto medial da articulação ficou à esquerda do monitor e o aspecto lateral à direita. A articulação foi examinada em seus aspectos cranial, craniolateral e craniomedial. O exame dinâmico incluiu movimentos de flexão e extensão bem como de rotação interna e externa do joelho, de acordo com a estrutura a ser estudada. As orientações anatômicas para a posição do transdutor foram a patela e os côndilos lateral e medial da tíbia e do fêmur. Os cortes foram efetuados nas regiões suprapatelar, infrapatelar, lateral e medial.

\section{RESULTADOS E DISCUSSÃO}

Pelos exames radiográficos observou-se, como referido por Allen et al. (1998), ser o côndilo femoral lateral mais amplo que o côndilo medial, especialmente na incidência

\footnotetext{
12 Modelo D800, TUR-DRESDEN Corporation.

${ }^{13}$ MXG/PLUS, KODAK Brasileira Comércio e Indústria Ltda.

${ }^{14}$ LANEX REGULADOR, KODAK Brasileira Comércio e Indústria Ltda.

15 MACROTEC Ind. e Com. de Equipamentos Ltda, Rua San José 676, Cotia, SP.

${ }^{16}$ GE MEDICAL SYSTEMS, 2 North Yong Chang Road 3000, 100176 Beijin, China.
}

craniocaudal. Adicionalmente, na mesma incidência, notou-se ser o côndilo tibial lateral maior em relação ao medial, o que promove uma maior área de superfície articular. Por sua vez, a depressão verificada na margem lateral no côndilo femoral lateral provavelmente corresponde à origem do ligamento colateral lateral, que em ovinos origina o tendão dos músculos fibular longo, extensor lateral dos dedos e flexor profundo dos dedos (Sisson 1986c).

O fato de a patela apresentar, na incidência mediolateral, uma base em formato piramidal e ápice afilado pode ter relação com a presença dos ligamentos patelares lateral, intermédio e medial -, os quais consistem em três bandas muito fortes que conectam a patela à tuberosidade da tíbia (Sisson 1986a). Além disso, conforme Allan et al. (1998), no aspecto caudal, a patela é lisa e forma a superfície articular, que é convexa na direção mediolateral e côncava na direção proximodistal, fato também constatado na incidência mediolateral.

Dos 36 membros avaliados, o osso sesamóide medial do músculo gastrocnêmio foi visibilizado radiograficamente somente em um membro $(2,7 \%)$ e o osso sesamóide lateral em quatro $(11,1 \%)$. Acredita-se que essa diferença anatômica quando comparado aos cães, que possuem tanto o osso sesamóide lateral como o medial, possa impedir a utilização de técnicas extra-articulares para o tratamento de lesões no ligamento cruzado cranial (Piermattei et al. 2006). Quanto à fíbula, essa foi identificada em apenas um animal do Grupo III (Fig.1). Como referido por outros autores (Sisson 1986b, Allen et al. 1998), em ovinos a fíbula é considerada vestigial, não tem corpo e con-

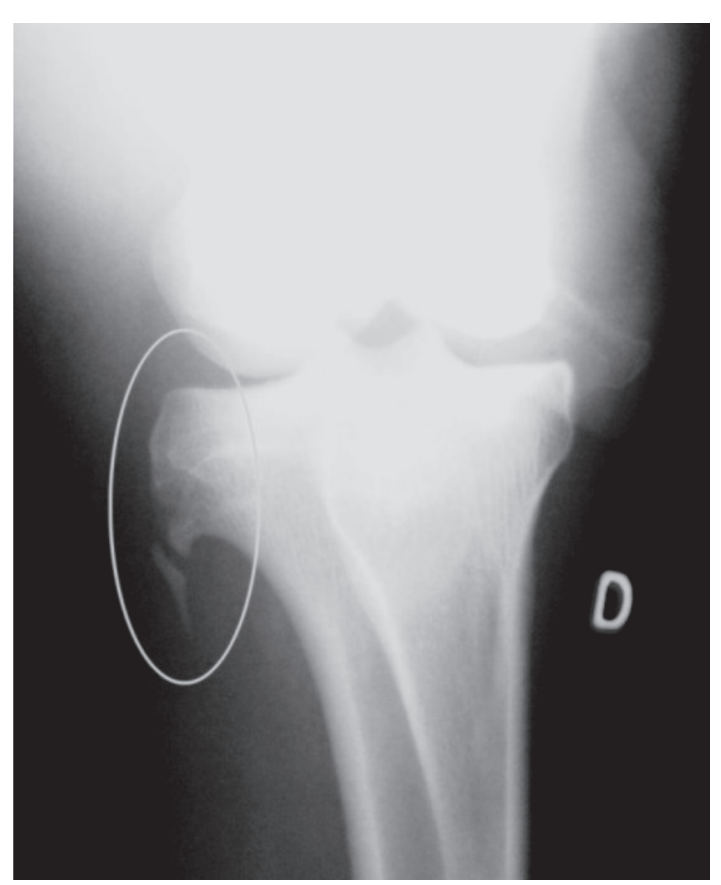

Fig.1. Imagem radiográfica, em projeção craniocaudal, do joeIho direito de um ovino do Grupo III. Nota-se a presença da extremidade proximal da fíbula vestigial (círculo). 
siste apenas das extremidades (Sisson 1986b, Allen et al. 1998) o que provavelmente limita o uso desta espécie para procedimentos ortopédicos que utilizam a fíbula, como enxerto livre ou vascularizado, como nos casos de perda óssea segmentar (LaVelle 2003).

A maioria dos ovinos apresentou superfície do osso subcondral lisa em ambos os côndilos femorais, sendo $75 \%$ nos Grupos I e III e 91,6\% no Grupo II, considerando ambos os joelhos. A irregularidade de Grau 2 somente foi verificada em animais do Grupo I em um dos côndilos, os demais apresentaram irregularidade de Grau 1 que, em sua maior parte, também ocorriam em apenas um dos côndilos. Em virtude da idade associada à baixa ocorrência e pouca intensidade, essas irregularidades não foram consideradas alterações patológicas. Além disso, todos os animais se locomoviam sem demonstrar sinais clínicos de claudicação e não foram observados outros sinais radiográficos de doença articular degenerativa, tais como estreitamento do espaço articular, osteofitose, entesopatia, esclerose ou cistos subcondrais e aumento do fluido sinovial (Widmer \& Blevins 1994, Carrig 1997, Mahaffey 1998).

Nos ovinos do Grupo I (idade de 6-8 meses), as linhas fisárias femoral distal e tibial proximal estavam abertas em $83,33 \%$ dos membros $(n=10)$ e semifechadas em $16,66 \%(n=2)$. Já a tuberosidade tibial encontrava-se abertas em todos (Fig.2) (Quadro 1). Nos animais do Grupo II (idade de 2 anos), 66,66\% ( $n=8$ ) dos membros tinham as linhas fisárias femoral distal e tibial proximal semifechadas, e o restante deles $(n=4)$ fechada. Além disso, todos os animais possuíam a tuberosidade tibial semifechada. Contudo, no Grupo III (idade de 3-5 anos), a tuberosidade tibial apresentava-se totalmente fechada em metade dos membros $(n=6)$ e a outra metade ainda possuía a porção distal da tuberosidade aberta, e em $8,33 \%(n=1)$ dos membros, as linhas fisárias femoral distal e tibial proximal encontravam-se ainda semifechadas. Como referido por Sisson (1986b), em pequenos ruminantes a época da fusão da placa fisária do fêmur distal e tíbia proximal ocorre aproximadamente aos três anos e meio de idade.

O exame ultra-sonográfico do joelho dos ovinos no presente experimento foi realizado por regiões (suprapatelar, infrapatelar, lateral e medial), baseado no padrão adotado por Kramer et al. (1999) para cães, e permitiu uma análise de forma sistemática. A metodologia foi simi-

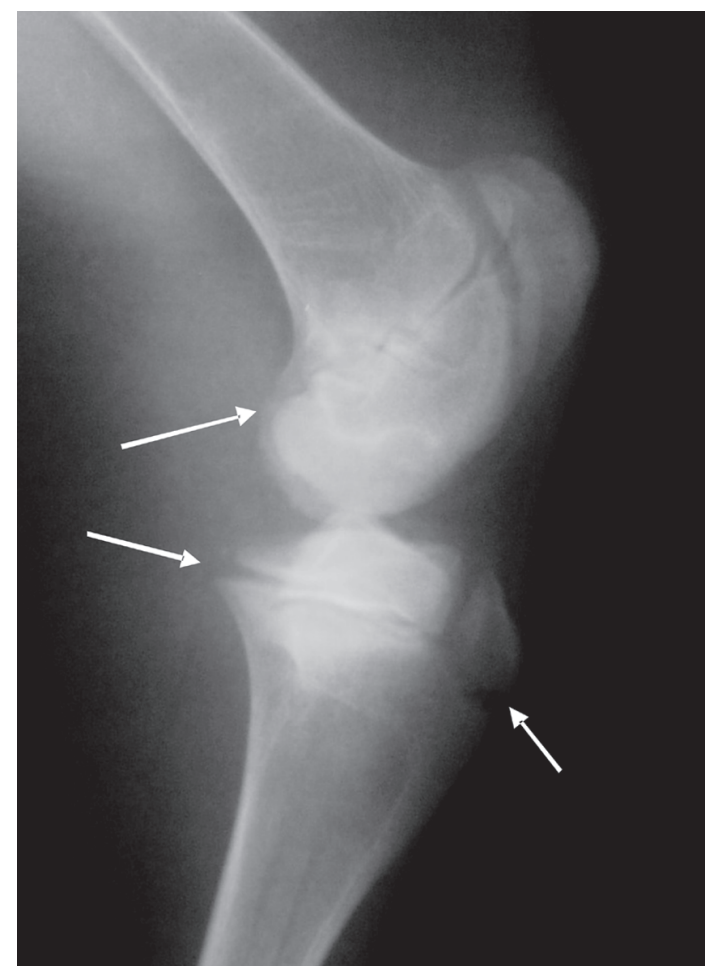

Fig.2. Imagem radiográfica em projeção mediolateral do joelho, em ovino do Grupo I. Observar que as linhas fisárias femoral distal, tibial proximal e da tuberosidade da tíbia estão abertas (setas).

lar a de um outro estudo com ovinos, em que o joelho foi avaliado em flexão, nos eixos longitudinal e transversal, porém com o transdutor colocado nos aspectos cranial, craniolateral e craniomedial e não nas regiões supracitadas (Macrae \& Scott 1999).

No plano longitudinal e central da região suprapatelar, a superfície convexa da patela foi visibilizada pelo exame ultra-sonográfico como uma linha hiperecogênica com sombra acústica em todos os grupos. Em outras pesquisas as superfícies ósseas também foram identificadas como linhas ecogênicas com sombra acústica, tanto nos côndilos femorais e platô tibial de cães (Reed et al. 1995), como na tróclea, patela e côndilos da tíbia de ovinos (Macrae \& Scott 1999). Na análise da região infrapatelar, em plano longitudinal, a cartilagem articular dos côndilos femorais foi ob-

Quadro 1. Avaliação radiográfica quanto à presença (aberta ou semifechada) ou ausência de linha radiolucente das placas fisárias femoral distal, tibial proximal e da tuberosidade tibial, em ovinos dos Grupos I, II e III

\begin{tabular}{|c|c|c|c|c|c|c|}
\hline \multirow{2}{*}{$\begin{array}{l}\text { Linhas } \\
\text { fisárias }\end{array}$} & \multicolumn{2}{|c|}{ Grupo I (6-8 meses) } & \multicolumn{2}{|c|}{ Grupo II (2 anos) } & \multicolumn{2}{|c|}{ Grupo III (3-5 anos) } \\
\hline & Aberta & Semifechada & Semifechada & Fechada & Semifechada & Fechada \\
\hline $\begin{array}{c}\text { Femoral } \\
\text { distal }\end{array}$ & $\begin{array}{l}83,33 \% \\
(10 / 12)\end{array}$ & $\begin{array}{c}16,66 \% \\
(2 / 12)\end{array}$ & $\begin{array}{c}66,66 \% \\
(8 / 12)\end{array}$ & $\begin{array}{c}33,34 \% \\
(4 / 12)\end{array}$ & $\begin{array}{l}8,33 \% \\
(1 / 12)\end{array}$ & $\begin{array}{c}91,66 \% \\
(11 / 12)\end{array}$ \\
\hline $\begin{array}{c}\text { Tibial } \\
\text { proximal }\end{array}$ & $\begin{array}{l}83,33 \% \\
(10 / 12)\end{array}$ & $\begin{array}{c}16,66 \% \\
(2 / 12)\end{array}$ & $\begin{array}{c}66,66 \% \\
(8 / 12)\end{array}$ & $\begin{array}{c}33,34 \% \\
(4 / 12)\end{array}$ & $\begin{array}{l}8,33 \% \\
(1 / 12)\end{array}$ & $\begin{array}{c}91,66 \% \\
(11 / 12)\end{array}$ \\
\hline $\begin{array}{c}\text { Tuberosidade } \\
\text { da tíbia }\end{array}$ & $\begin{array}{c}100 \% \\
(12 / 12)\end{array}$ & - & $\begin{array}{c}100 \% \\
(12 / 12)\end{array}$ & - & $\begin{array}{l}50 \% \\
(6 / 12)\end{array}$ & $\begin{array}{l}50 \% \\
(6 / 12)\end{array}$ \\
\hline
\end{tabular}




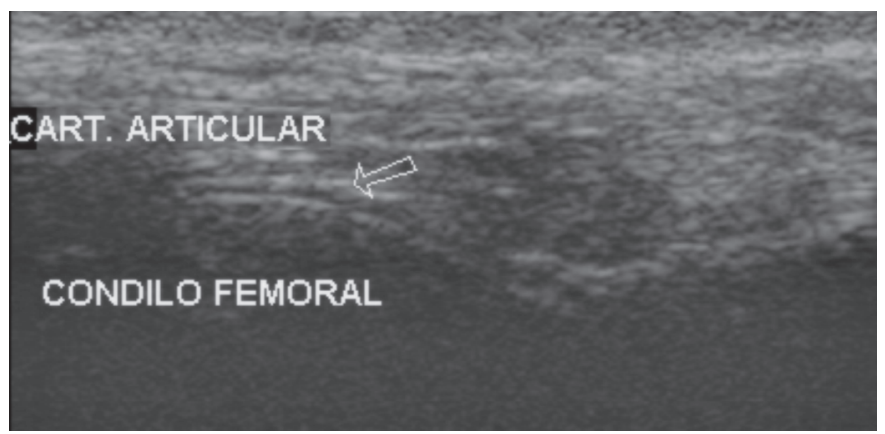

Fig.3. Imagem ultra-sonográfica no plano longitudinal do joelho de ovino do Grupo II. Nota-se a cartilagem articular como uma linha hipoecogênica contornando a superfície óssea do côndilo femoral (seta).

servada em todos os animais como uma linha hipoecogênica contornando a superfície óssea (Fig.3). De forma similar, Macrae \& Scott (1999) identificaram a cartilagem articular do joelho de ovinos como imagem hipoecóica distinta e lisa entre duas linhas hiperecóicas (interfaces entre a cartilagem do tecido mole e osso subcondral). A membrana sinovial não foi objeto de análise no presente estudo, embora outros autores a avaliem pelo exame ultra-sonográfico (Reed et al. 1995, Carrig 1997).

Nos ovinos do presente experimento, o ligamento patelar intermédio mostrou-se como uma estrutura fibrilar hiperecogênica homogênea com espessura de 1,2-3,2mm. Por outro lado, em estudo ultra-sonográfico com cães hígidos, o ligamento patelar foi visto como uma estrutura homogênea de baixa a moderada ecogenicidade, com espessura de 1,3-2,3 mm (Reed et al. 1995).

Quanto aos ligamentos cruzados, foi possível verificar apenas a inserção do ligamento cruzado cranial como uma imagem hipoecogênica na área intercondilar central da tíbia (Fig.4), estando todos os animais em flexão. Em cães, os ligamentos cruzados foram identificados em plano

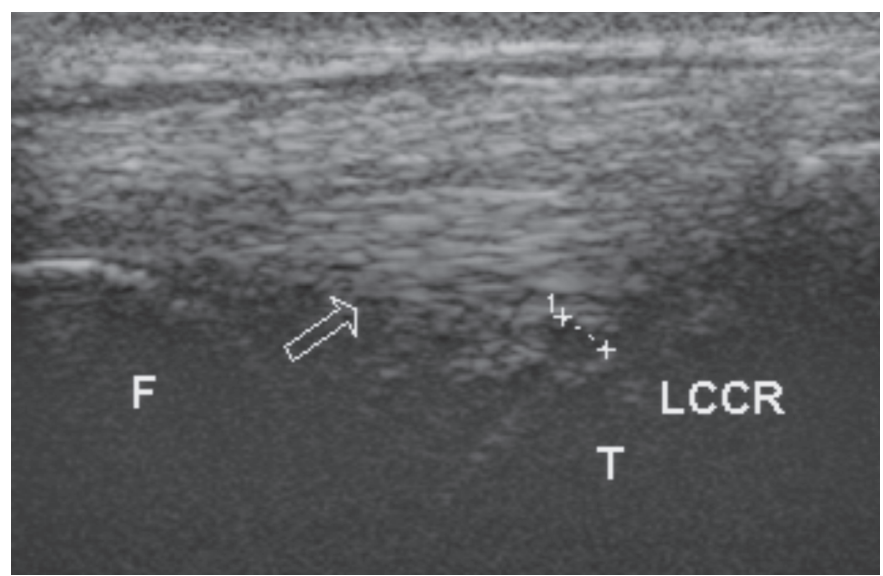

Fig.4. Imagem ultra-sonográfica no plano longitudinal do joelho de ovino do Grupo II. Verifica-se a imagem hipoecogênica na área intercondilar central da tíbia correspondente à inserção do ligamento cruzado cranial (entre +) (LCCR), ( $F=$ fêmur, $\mathrm{T}$ = tíbia, seta = ligamento patelar).

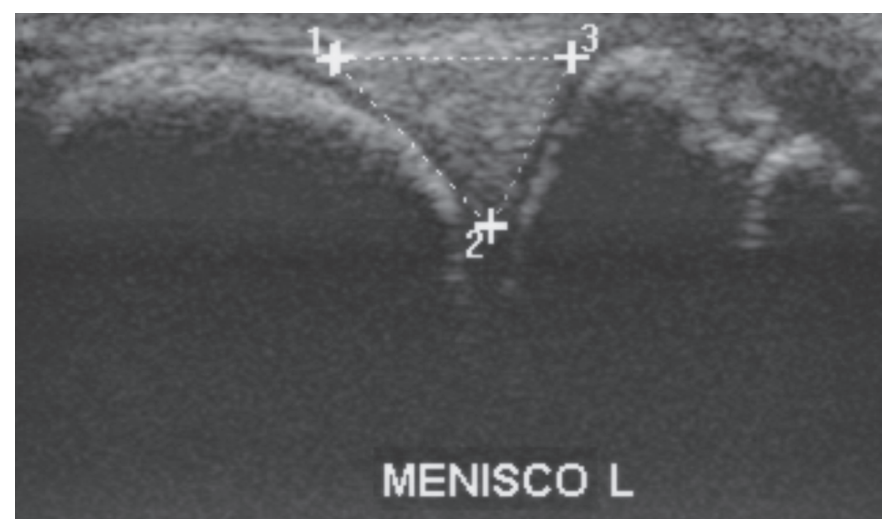

Fig.5. Imagem ultra-sonográfica da região craniolateral, em plano longitudinal, do joelho de ovino do Grupo I. Nota-se o menisco lateral com formato triangular, aspecto discretamente heterogêneo e ecogenicidade moderada.

mediosagital com o membro em total flexão (Reed et al. 1995), porém o ligamento cruzado caudal não pode ser visibilizado por Kramer et al. (1999), quando analisada a região caudal. Segundo Reed et al. (1995), o ligamento cruzado cranial apresenta-se mais hipoecogênico que o ligamento patelar.

Os meniscos - lateral e medial - foram facilmente identificados no plano longitudinal em todos os ovinos e apresentaram formato triangular, de aspecto discretamente heterogêneo e ecogenicidade moderada (Fig.5). Esse aspecto heterogêneo foi descrito em cães como edema de menisco (Kramer et al. 1999), porém mostrou ser a imagem normal nos animais do presente estudo. Ao avaliarem a articulação de cães hígidos, Reed et al. (1995) também visibilizaram os meniscos, em imagens sagitais, todavia, como estruturas homogêneas, ecogênicas e triangulares, com o ápice do triângulo apontado axialmente.

Ressalta-se que em ovinos ambos os meniscos são unidos à tíbia por dois ligamentos curtos (cranial e caudal), o ligamento intermeniscal conecta as bordas craniais dos dois meniscos e o único ligamento meniscofemoral origina-se do corno caudal do menisco lateral e insere-se na região intercondilar medial do fêmur (Allen et al. 1998). Esse último é mais forte e mais largo quando comparado ao de humanos, provavelmente porque além de contribuir significantemente para controlar a estabilidade craniocaudal e rotatória interna-externa. Em ovinos o corno posterior do menisco lateral parece atuar como uma tipóia, suportando o côndilo femoral lateral em flexão (Gupte et al. 2003). No entanto, assim como em cães (Reed et al. 1995), não foi possível visibilizar esses ligamentos meniscais e intermeniscais pelo exame ultrasonográfico.

Em nenhuma articulação foi constatada imagem anecogênica de líquido. Macrae \& Scott (1999) utilizando os mesmos planos de aquisição de imagens, também afirmaram ser inconsistente a identificação de fluido sinovial no joelho de ovinos hígidos. 


\section{CONCLUSÕES}

Foi possível concluir que, em ovinos hígidos: o exame radiográfico é útil para avaliar especialmente as estruturas ósseas do joelho e o fechamento das placas fisárias, esse último mais evidente naqueles entre 3 e 5 anos idade; e a ultra-sonografia permite identificar algumas estruturas teciduais moles, como os meniscos e o ligamento patelar.

Agradecimentos.- Ao Conselho Nacional de Desenvolvimento Científico e Tecnológico (CNPq) pelo apoio financeiro (Edital Universal, Proc. 473.637/2004-9) e a FAPESP (Proc.06/59.367-7) pela bolsa de mestrado.

\section{REFERÊNCIAS}

Allan G. 1998. Radiographic signs of joint disease, p.169-188. In: Thrall D.E. (ed.), Textbook of Veterinary Diagnostic Radiology. $3^{\text {rd }}$ ed. W.B. Saunders, Philadelphia. 660p.

Allen M.J., Houton J.E.F., Adams S.B. \& Rushton N. 1998. The surgical anatomy of the stifle joint in sheep. Vet. Surg. 27:596-605.

Carrig C.B. 1997. Diagnostic imaging of osteoarthritis. Vet. Clin. North Am., Small Anim. Clin. 27(4):777-813.

Dürselen L., Claes L., Ignatius A. \& Rübenacker S. 1996. Comparative animal study of three ligament prostheses for the replacement of the anterior cruciate and medial collateral ligament. Biomaterials 17(10):977-982.

Freeman M.A.R. \& Pinskerova V. 2003. The movement of the knee studied by magnetic resonance imaging. Clin. Orthop. Related Res. 1(410):35-43.

Gupte C.M., Jeevan D., Bull A.M.J. \& Amis A.A. 2003. The meniscofemoral ligament. Vet. Comp. Orthop. Traumatol. 16:26-31.

Jackson D.W., Mcdevitt C.A., Simon T.M., Arnoczky S.P., Atwell E.A. \& Silvino N.J. 1992. Meniscal transplantation using fresh and cryopreserved allografts. Am. J. Sports Med. 20(6):644-656.

Kelly B.T., Potter H.G., Deng X.H., Pearle A.D., Turner A.S., Warren R.F. \& Rodeo S.A. 2006. Meniscal allograft transplantation in the sheep knee: evaluation of chondroprotective effects. Am. J. Sports Med. 34(90):1464-1478.

Kramer M., Stengel H., Gerwing M., Schimke E. \& Sheppard C. 1999.
Sonography of the canine stifle. Vet. Radiol. Ultrasound 40(3):282293.

LaVelle D.G. 2003. Delayed union and nonunion of fractures, p.31253165. In: Canale S.T. (ed.), Campbell's Operative Orthopaedics. $10^{\text {th }}$ ed. Mosby, Philadelphia.

Macrae A.I. \& Scott P.R. 1999. The normal ultrasonographic appearance of ovine joints, and uses of arthrosonography in the evaluation of chronic ovine joint disease. Vet. J. 158(2):135-143.

Mahn M.M., Cook J.L., Cook C.R. \& Balke M.T. 2005. Arthroscopic verification of ultrasonographic diagnosis of meniscal pathology in dogs. Vet. Surg. 34:318-323.

Mahaffey M.B. 1998. The stifle and tarsus, p.194-199. In: Thrall D.E. (ed.), Textbook of Veterinary Diagnostic Radiology. $3^{\text {rd }}$ ed. W.B. Saunders, Philadelphia. 660p.

Piermattei D.L., Flo G.L. \& DeCamp C.E. 2006. The stifle joint, p.562632. In: _ (ed.), Handbook of Small Animal Orthopedics and Fracture Repair. $4^{\text {th }}$ ed. Saunders Elsevier, St Louis. 832p.

Reed A.L., Payne J.T. \& Constatinescu G.M. 1995. Ultrasonographic anatomy of the normal canine stifle. Vet. Radiol. Ultrasound 36(4):315321.

Sisson S. 1986a. Articulações do eqüino, p.324-349. In: Sisson S. \& Grossman J.D. (ed.), Getty's Anatomia dos Animais Domésticos. Vol.1. $5^{\mathrm{a}}$ ed. Guanabara Koogan, Rio de Janeiro. 1134p.

Sisson S. 1986b. Osteologia ruminante, p.693-735. In: Sisson S. \& Grossman J.D. (ed.), Getty's Anatomia dos Animais Domésticos. Vol.1. $5^{\mathrm{a}}$ ed. Guanabara Koogan, Rio de Janeiro. 1134p.

Sisson S. 1986c. Músculos do ruminante, p.740-806. In: Sisson S. \& Grossman J.D. (ed.), Getty's Anatomia dos Animais Domésticos. Vol.1. $5^{\underline{a}}$ ed. Guanabara Koogan, Rio de janeiro. 1134p.

Stickle R.L. \& Hathcock J.T. 1993. Interpretation of computed tomographic images. Vet. Clin. North Am., Small Anim. Clin. 23(2):417-435.

Szomor Z.L., Martin T.E., Bonar F.M.B. \& Murrell G. 2000. The protective effects of meniscal transplantation on cartilage: an experimental study in sheep. J. Bone Joint Surg. Am. 82:80-88.

Torelli S.R., Rahal S.C., Volpi R.S., Yamashita S., Mamprim M.J. \& Crocci A.J. 2004. Radiography, computed tomography and magnetic resonance imaging at 0.5 Tesla of mechanically induced osteoarthritis in rabbit knees. J. Med. Biol. Res. 37(4):493-501.

Widmer W.R. \& Blevins W.E. 1994. Radiographic evaluation of degenerative joint disease in horses: interpretive principles. Compend. Cont. Educ. Pract. Vet. 16(7):907-917. 